\title{
Experience of using distance technology to teach Chinese undergraduates during the COVID-19 pandemic
}

\author{
Olga Fedotova ${ }^{1, *}$, Elena Platonova ${ }^{2}$, Vladimir Latun $^{3}$, Igor Filkevich ${ }^{2}$ and Oleg Igumnov ${ }^{2}$ \\ ${ }^{1}$ Don State Technical University, Gagarin Sq, 1, Rostov on Don, 344003, Russia \\ ${ }^{2}$ Moscow Pedagogical State University, Institute of Social Studies and Humanities, 119571, Moscow, \\ Russia \\ ${ }^{3}$ Southern Federal University, Bolshaya Sadovaya, 105, Rostov on Don, 344000, Russia
}

\begin{abstract}
The COVID-19 pandemic has significantly affected the organization of the educational process in Russian universities. The object of the research is the experience of implementing e-education and the transition to distance technologies for continuing education of Chinese undergraduates in the Russian metropolitan university. Russian universities had the technical capabilities and used various electronic educational platforms. In the same time, the results of the survey showed a decrease in the satisfaction of Chinese full-time students when switching to distance learning. The study shows the significant factors that had a negative impact on the educational process using distance technology to teach Chinese undergraduates during the COVID-19 pandemic. The authors have grouped these factors into five groups (technical, language, emotional, and financial, content of lecture). Identification of these factors made it possible to develop a program to improve the educational process and enhance the satisfaction of foreign students studying at Russian universities.
\end{abstract}

\section{Introduction}

The rapid spread of COVID-19 infection since January 2020 has become a pandemic and has made significant adjustments to the organization of the educational process in Russian universities. The transition of Russian universities to e-learning and the widespread use of distance learning technologies entirely was a landmark event for the Russian educational environment. That forced measure by the decision of the state authorities of Russia was necessary in order to preserve the health of students and employees of all universities.

Before the introduction of electronic education in all Russian universities in connection with a new coronavirus infection, Russian universities had accumulated some experience in using educational technologies based on information and telecommunications networks, which ensured the interaction of students and teachers at a distance. All Russian universities had the technical capabilities and used various electronic educational platforms. Most of the teachers of Russian universities were trained in retraining programs and teachers had the

\footnotetext{
*Corresponding author: fod1953@yandex.ru
} 
appropriate knowledge to work on electronic educational platforms before switching to electronic training entirely [1].

However, until March 2020, full-time education in Russian universities was based on the combined use of traditional forms of education in the form of classroom studies (lectures, seminars, practical exercises) and the work of students using electronic educational platforms for performing extracurricular tasks. Students have received the individual tasks for the fulfillment of projects, abstracts, essays, videos and other educational tasks and posted the results of the completed tasks on an electronic platform for verification by the teacher.

The usage of electronic platforms by students and teachers of Russian universities in the learning process was of an auxiliary nature. In full-time education, the main form of interaction between students and teachers was direct contacts between students and professors during lectures, seminars, and practical classes. Transfer to distance technologies entirely in the educational process required teachers to restructure the teaching methodology, and students needed to restructure the process of perceiving educational material $[2,3,4]$.

Over the past years, the Russian schools have been actively developing teaching methods using distance technologies for different age categories of children [5,6]. Basically, the methods of e learning are good presented in the teaching and methodological literature for correspondence education in Universities, and E-portfolio as well [7]. The authors of teaching methods using distance technologies did not assume the situation of the complete transition of students of full-time courses to e-learning in case of abandoning traditional forms of conducting classes $[8,9]$.

In a special situation were many Chinese students of Russian universities who left for their homeland for holidays in January 2020, and could not return due to an unfavorable epidemiological situation [10]. For this group of students, the use of distance technologies was the opportunity to continue continuous study at Russian universities only. The fact of the transition to e-learning for the foreign students who are faced with the closure of state borders can be attributed as the positive result of the decision and monitoring of state bodies [11].

The main objective of our work is to describe some results of the experience of using distance technologies for teaching Chinese undergraduates, highlighting the negative factors in mastering the educational material and determining the satisfaction of Chinese undergraduates with the results of e-learning in the second semester of the 2019/2020 academic year.

\section{Methodology}

Research methods are included survey, questioning, statistic and graphic methods, generalization, comparison, and interpretation [12, 13].

The Department of Economic Theory and Management of the Moscow Pedagogical State University (MPSU) conducted a survey on the results of distance learning at the end of the summer examination session in June 2020. Totally 52 Chinese undergraduates of the first year of training in the field of training 38.04.02 Management took part in the questionnaire and survey. Chinese undergraduates masters the master's program of "Financial and International Business Management".

Among those who involved in the study, 46 undergraduates remained by the period of transition to distance technologies in China (first group) and 6 undergraduates mastered the master's program while staying in Russia (second group).

Each participant in the survey was asked to express their attitude to the transfer to distance technologies entirely by setting points on a point system from zero (minimum) to ten (maximum). At the same time, the minimum number of points meant a negative rating (1-3), medium rating (4-7) and points above eight meant a positive score by a master's student. 


\section{Results and discussion}

The study allows us to assess the experience of using distance technology to teach Chinese underground during the COVID-19 pandemic.

The first survey of all groups of undergraduates was conducted at the very beginning of the transition to distance learning in order to ascertain the expectations of undergraduates from the results of training. The results of the expectations of undergraduates are presented in Fig. 1.

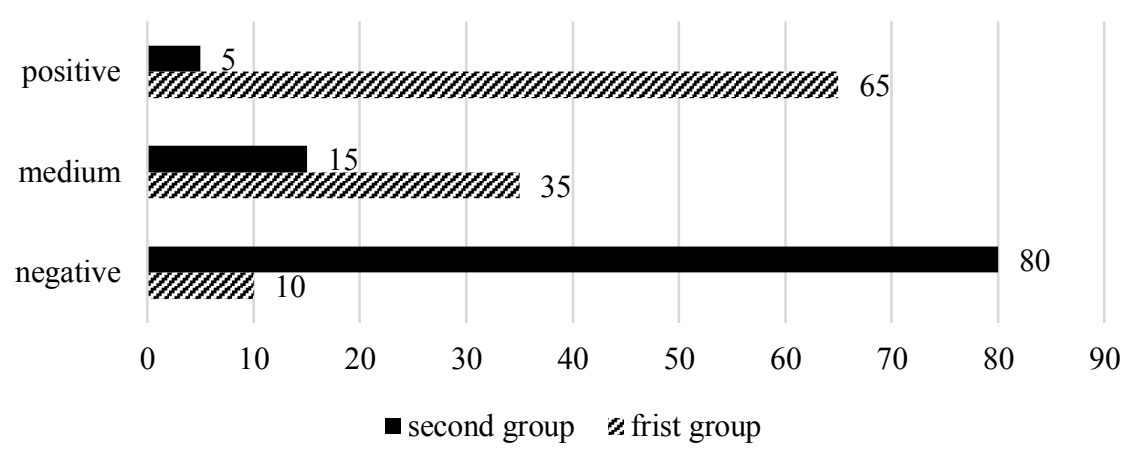

Fig. 1. Distribution of the expectations of undergraduates about the distance technologies in March 2020 (by groups, $\% \%$ ).

As follows from data Figure 1, the undergraduates who were in Russia strove to conduct classes in a traditional manner. While the undergraduates who could not return after the holidays highly appreciated the opportunity to continue their studies, including the distance technologies.

After the end of the second semester, during which distance technologies were used, a second survey with the question on the satisfaction of undergraduates with the full transfer to distance technologies in the magistracy was conducted. The assessments of undergraduates are presented in Figure 2.

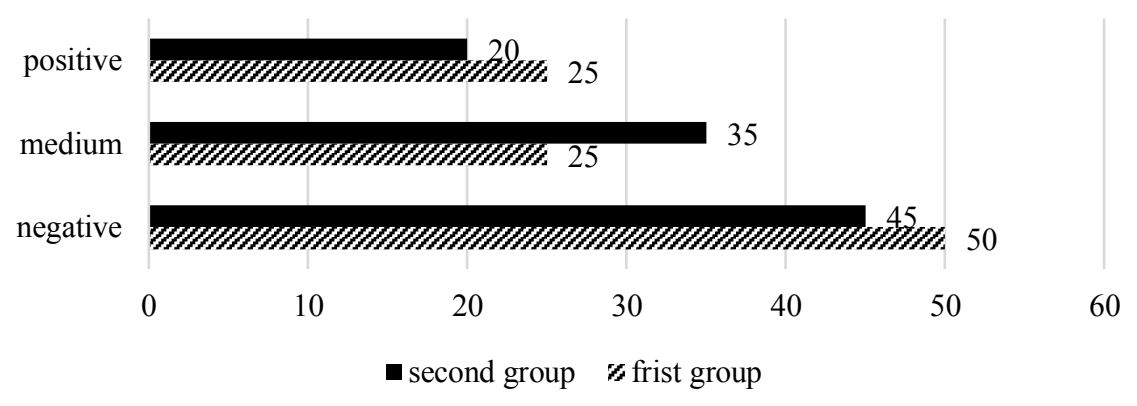

Fig. 2. Distribution of assessments by undergraduates of learning outcomes using distance technologies entirely (by groups, $\% \%$ ).

Figure 2 shows a significant increase in the negative attitude of undergraduates of the first group to the use of distance technologies only. In the second group of undergraduates, there is an opposite tendency and an increase in the number of undergraduates, who more 
positively assessed training with a full transition to distance technologies. The results of the survey on the satisfaction of undergraduates with training with a full transition to distance technologies required a deep analysis of this situation.

Chinese master's students make up a significant part of the number of undergraduates in the Master's program of "Financial and International Business Management". In 2019, the Department of Economic Theory and Management of the MPSU has conducted surveys of undergraduates of previous graduations and received a high assessment of the content of the taught disciplines of all block of curriculum of Master's program and the pedagogical skills of the department teachers.

It was decided to hold a detailed survey with additional questions to identify main reasons of the dissatisfaction of master's students. Undergraduates were asked to choice some factors that negatively influenced the educational process using distance technologies entirely. As in the first surveys, undergraduates used a point system and assessed the negative influence of one or another proposed factor from zero (weak influence) to ten (strong influence). If more than half of the undergraduates of each group assessed the effect of the factor from zero to three, then this factor was not taken into account as having a negative impact on the educational process.

After processing the survey data of the first and second groups of undergraduates, the most significant factors that had a negative impact on the educational process were identified as it shows in Figure 3.

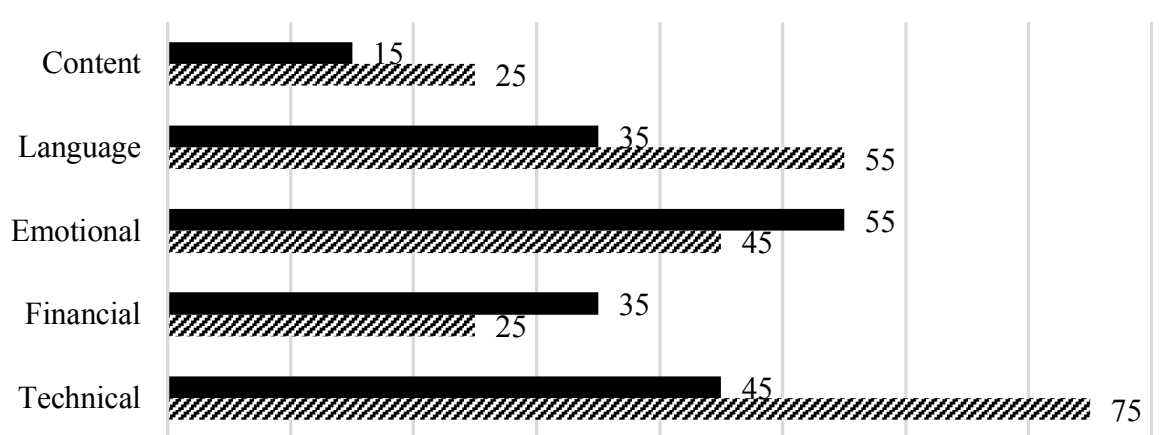

- second group $\approx$ frist group

Fig. 3. Negative factors affecting the educational process using distance technologies entirely (according to a survey of Chinese undergraduates, by groups, \%\%).

As follows from data, the technical factors have the greatest negative impact, among which Chinese undergraduates have noted the difficulties in entering the university's electronic information platform; incomprehensible interface of the university's electronic information platform; an unstable connection to the university's electronic platform; a need to have computer equipment high quality.

During distance learning, Chinese undergraduates have had difficulty understanding the lecture material in Russian. That fact can be combined with the emotional factor in view of the lack of personal direct contact of the student with the teacher and fellow students. Undergraduates have noted the emergence of a sense of loneliness and the need for communication and discussion during the educational process. Our experience has shown when switching to distance learning entirely, teachers need to use interactive teaching methods. This conclusion is shared with the conclusions of other researchers $[14,15]$.

The negative perception of the transition to distance learning by undergraduates was influenced by the financial factor. Undergraduates have expected a reduction pricing the 
training on the base of the distance technologies. According to the data, approximately 25$35 \%$ of undergraduates have considered reducing the contractual cost of distance learning to be a fair measure.

\section{Conclusion}

Our study showed that by the beginning of the pandemic, MSPU has had the technical capabilities and the necessary electronic information educational platform based on Moodle, the potential of which was realized for correspondence education mainly.

In the course of the research, it was revealed that the foreign undergraduates have difficulties in quickly switching to the use of distance technologies. The foreign undergraduates prefer the traditional forms of full-time education. The main groups of the negative factors affecting the educational process using distance-learning technologies entirely were identified based on a sequential survey of Chinese undergraduates.

Identification of these factors made it possible to develop a program to improve the educational process using distance technologies under the conditions of continuing restrictions due to a new coronavirus infection.

\section{References}

1. O. Fedotova, V. Latun, N. Moskovskaya, ICEEPSY 2018 Proceeding 53, 733-739 (2019)

2. J. Bierne, A. Svirina, J. Titko, Notes in Networks and Systems 68, 768-778 (2019)

3. L. Lisitsyna, A. Lyamin, A. Skshidlevsky, Frontiers in Artificial Intelligence and Applications 262, 732-738 (2014)

4. A. Fedosov, International Multidisciplinary Scientific Conferences on Social Sciences and Arts (SGEM 2015), 281-286 (2015)

5. Y.H. Wang, Computers \& Education 156, 103-105 (2020)

6. C. Herodotou, D.K. Muirhead et al., Higher Education Interactive Learning Environments 28(6), 713-728. (2020).

7. M. Aparicio, F. Bacao, T. Oliveira, Educational Technology \& Society 19, 292-307 (2016)

8. T. Chen, R.S. Robin Snell, C.W. Wu, Academy of Management Learning \& Education 17(4), 474-495 (2018)

9. O. Fedotova, V. Latun, E. Platonova, I. Okuneva, EDULEARN17 Proceeding, 88868890 (2017)

10. E. Platonova, O. Fedotova, et al., EDULEARN18 Proceedings, 10105-10111 (2018)

11. E. Platonova, O. Fedotova, J. Bogomolova, ICERI 2017 Proceeding, 6861-6866 (2017)

12. M. Zhizhina, Mediaobrazovanie-media education 4, 47-65 (2016)

13. Y. Bystray, E. Baronenko et al., Humanities and Social Sciences Reviews 7(6), 946-953 (2019)

14. F. Khonamri, M. Azizi, R. Kralik, Science for Education Today 10(1), 25-42 (2020)

15. T. Garnett, D. Button, Nurse Education in Practice 32, 1-8 (2018) 